\title{
Optimizing transportation in the precast concrete plants
}

\author{
Aleksander Nicał ${ }^{1}$ \\ Received: 28 September 2020 / Accepted: 23 April 2021 / Published online: 13 May 2021 \\ (C) The Author(s) 2021
}

\begin{abstract}
In addition to aggregates, cement, water and reinforcement, transportation is one of the key aspects in operating a precast concrete manufacturing plant. The cost of transportation in precast concrete manufacturing plants is closely related to electricity prices. Despite intensive efforts to implement renewable energy sources, still, 2/3 are non-renewable sources, such as coal, natural gas and oil. Taking into account the negative impact on the environment associated with the exploration of non-renewable resources and the observed increase in electricity prices, it is necessary to find alternative solutions that minimize environmental and financial costs. The paper presents a model for the selection of optimal transportation system inside the precast concrete manufacturing plant. It ensures the fullest possible use of equipment resources, in this case, rail trolleys capacity, and minimization of their journey number. The paper describes three internal transportation systems that are shuttle, radial and circular. Moreover, the paper contains a case study, concerning the determination of the optimal transportation program between workstations. As a result of the analyses carried out, a model was developed, including the strategy of journey planning with the assumption of minimum costs and maximum use of the capacity of rail trolleys.
\end{abstract}

Keywords Precast concrete plant $\cdot$ Transportation $\cdot$ Optimization $\cdot$ Cost

PACS $89.20 . \mathrm{Kk} \cdot 87.55 . \mathrm{de}$

\section{Introduction}

Transportation inside the precast concrete plants plays a very important role in the correct operation of production processes. Its cost significantly affects the price of the final products. Among the factors affecting the price of internal transport in the precast concrete plants is the cost of electricity, which has been increasing in recent years in most countries of the world. This is because most transportation equipment is powered by electricity. Despite many global activities in the field of implementing sustainable development, renewable energy sources are still a minority. It is doubtful, therefore, to look for savings in transport through the expected drop in electricity

This article is part of the Topical Collection on Geo-Resources-EarthEnvironmental Sciences

Responsible Editor: Iskender Akkurt

Aleksander Nicał

a.nical@il.pw.edu.pl

1 Faculty of Civil Engineering, Warsaw University of Technology, Warsaw, Poland prices. Considering this fact, it is, therefore, necessary to look for other ways to reduce the costs associated with the transportation of raw materials, and semi-finished and finished products in the precast concrete plants. Achieving this goal is possible through the proper organization and location of dispatch and collection points, selection of the appropriate type of transportation means and a high degree of automation. The selection of the appropriate type of transport means is based on technological, cost and organizational criteria. The technological aspect takes into account, among others, the dimensions, load capacity, travel speed, reliability and adaptability of transport means to the conditions of a given precast production plant. The cost aspect concerns selection of transport means with the objective function including the minimum costs of their work, purchase and repairs. The organizational aspect is related to the selection of an appropriate transportation system in such a way that the necessary road is as short as possible. Transportation optimization has been widely researched but in terms of public transport (Parbo et al. 2014). The studies conducted so far have included, among others, designing optimal combinations of selected tactics for public transport transfer synchronization (Nesheli and Ceder 2014), reducing the travel time by the automated construction of a robust railway table (Sels et al. 2016) or improving the 
punctuality of routes that operate using timetable analytical development and micro-simulations (Salicru et al. 2011). Despite the partial convergence of public and internal transport, it should be noted that the objective functions differ from each other when looking for optimal solutions. The specificity of operation in the precast concrete manufacturing plants with cyclical production often defines the condition of the minimum travelling distance with the smallest number of journeys between workstations. Fulfilling this condition, with the variability of transported tonnage, is possible only if the transportation system ensures the reduction or elimination of empty or underloaded journeys. The issue of precast concrete optimization in transportation planning and storage has been included in the component zoning strategy (Shin et al. 2008; 2005). In addition, in order to achieve optimization of resources and costs for the precast production of complex configurations, two new ideas have been adopted and incorporated into the mixed-integer linear programming model, namely prefabrication configuration and component groups (Khalli and Chua 2013). Linear programming has also been used in the model for optimizing reinforcement steel supplies for precast concrete plants and aggregate supplies for concrete plants (Nicał 2019; 2018a). Despite the extensive and in-depth research in this area, as well as other aspects of precast concrete plant operation regarding risk (Nicał et al. 2014), quality management (Nicał and Anysz 2019) and lean concept in manufacturing (Nicał 2018b), there is a lack of research in finding a model of transportation system optimisation for different tonnages between workstations. Considering the different delivery needs between every two workstations in a destination and return direction, the problem becomes complex. Therefore, it is necessary to develop a tool enabling finding the optimal transportation strategy, minimizing the cost, while meeting the needs of every workstation and taking into account the transportation means capacity. The issue of finding an appropriate transportation strategy is also partly related to decision-making problems in construction (Ibadov 2018) and project management with the use of precast concrete elements (Nicał and Wodyński 2015). High transportation costs inside precast concrete plants often have an impact on the cost of the entire construction project and require appropriate preventive measures at the project management stage. In this case, it might be necessary to treat transportation costs as a risk and implement appropriate measures to identify, measure and handle it (Ibadov 2016).

\section{Transportation in the precast concrete plants}

\section{Classification and characteristics of transportation in the precast plants}

Manufacturing processes consist of external and internal transport.
Internal transport includes the movement of materials, means of production, semi-finished products and finished products on the premises.

Proper internal transport should result in:

- the fastest flow of materials and their processing into a finished product,

- the lower labour intensity of the production process,

- less freezing of current assets,

- smaller production and storage space,

- lowering the own cost of the product.

Depending on the location of sending workstations and receiving workstations, as well as the nature of the production process and organization of transport, the following internal transportation organization systems are used (Table 1) (Radzikowski and Sarjusz-Wolski 1994).

External transport in precast concrete production industry concerns the supply of raw materials, semi-finished products and finished products to construction sites. As in the case of internal transportation, the main objectives should be to ensure the fastest possible flow of goods and to keep them lowcost, as well as to minimize storage space.

\section{Transportation cost analysis}

The price of internal transportation depends on many factors, among which the following can be mentioned:

- employee remuneration,

- depreciation of transportation equipment,

- electric energy consumption.

The costs of employee remuneration are related primarily to the necessary number of employee resources to ensure the proper operation of transport. Considering the cost optimization, it is generally more advantageous to use automated and possible worker-free transportation equipment, especially if the labour costs are high. Nowadays, autonomous trolleys are a common solution for internal transportation (PROMAG 2019).

Transportation equipment can usually be treated as fixed assets by the companies. Their depreciation period is influenced by the following factors, i.a.: technical condition, productivity, legal or other restrictions on the duration of use.

While employee remuneration and depreciation of transportation equipment are quite stable factors, generally dependent on local economic and legal conditions, electricity prices can be very changeable and dependent on a number of global factors. When analyzing the level of electricity prices for nonhousehold customers in the European Union and the Euro area in the last decade, there is a clear upward trend. For the EU, the price of $1 \mathrm{kWh}$ increased by an average of $16.58 \%$ over the 
Table 1 Internal transportation organization systems in precast concrete plants

\begin{tabular}{|c|c|}
\hline Internal transportation system description & Scheme of the transportation system \\
\hline $\begin{array}{l}\text { A shuttle system of transportation in which } \\
\text { communication is maintained between two } \\
\text { workstations. In this system, the means of } \\
\text { transportation usually go only one way with } \\
\text { the load and return empty. }\end{array}$ & \\
\hline $\begin{array}{l}\text { A radial system that links a sending } \\
\text { workstation or receiving workstation to } \\
\text { several receiving (or sending) workstations, } \\
\text { respectively. Means of transportation are } \\
\text { loaded in one direction only and return empty. }\end{array}$ & \\
\hline $\begin{array}{l}\text { A circular system, which is used in the case of } \\
\text { maintaining the transportation link between } \\
\text { several workstations, if the workstations are } \\
\text { located along a continuous line, and the } \\
\text { transportation takes place sequentially from } \\
\text { the first to the last workstation, in the same } \\
\text { direction. }\end{array}$ & \\
\hline
\end{tabular}

period from 2008 to 2018 . For the Euro area, at the same time, the increase was higher and amounted to $20.22 \%$. A detailed chart is shown in Fig. 1 (Eurostat 2019).

The upward trend of average retail electricity price also took place in the USA and amounted to $8.62 \%$ in the period 2008-2018 (Statista 2019). A detailed chart is shown in Fig. 2 (Eurostat 2019).

It should also be emphasized that the data from the past years indicate little chance of a decline in electricity prices. For example, between 2005 and October of 2015 , residential electricity prices increased by $34 \%$, while natural gas prices delivered to electric utilities declined by almost $60 \%$ and coal prices have remained essentially at the same level (INSTITUE FOR ENERGY RESEARCH 2016). Therefore, the general tendency should not be expected to reverse in the coming years. An additional argument in favour of maintaining this tendency is the still relatively high share of coal fuels in electricity generation worldwide, shown in Fig. 3 (World Coal Association 2020).
According to the figure above, coal-fuelled power plants currently fuel $38 \%$ of global electricity and, in some countries, coal fuels a higher percentage of electricity.

\section{Optimization of internal transportation}

One of the basic problems in transportation processes inside precast concrete plants is the selection of a transport system. The goal is to minimize the number of journeys required for a rail trolley between the following three work stations $(x, y, z)$ :

I-mould cleaning;

II-assembly of moulds;

III-casting.

A detailed transportation program inside the precast concrete production plant is presented in Table 2:

Before starting the calculation procedure, the following assumptions should be made:
Fig. 1 Development of average electricity prices for nonhousehold consumers including taxes, EU-28 and EA, 2008-2018 (EUR per kWh) (Eurostat 2019)

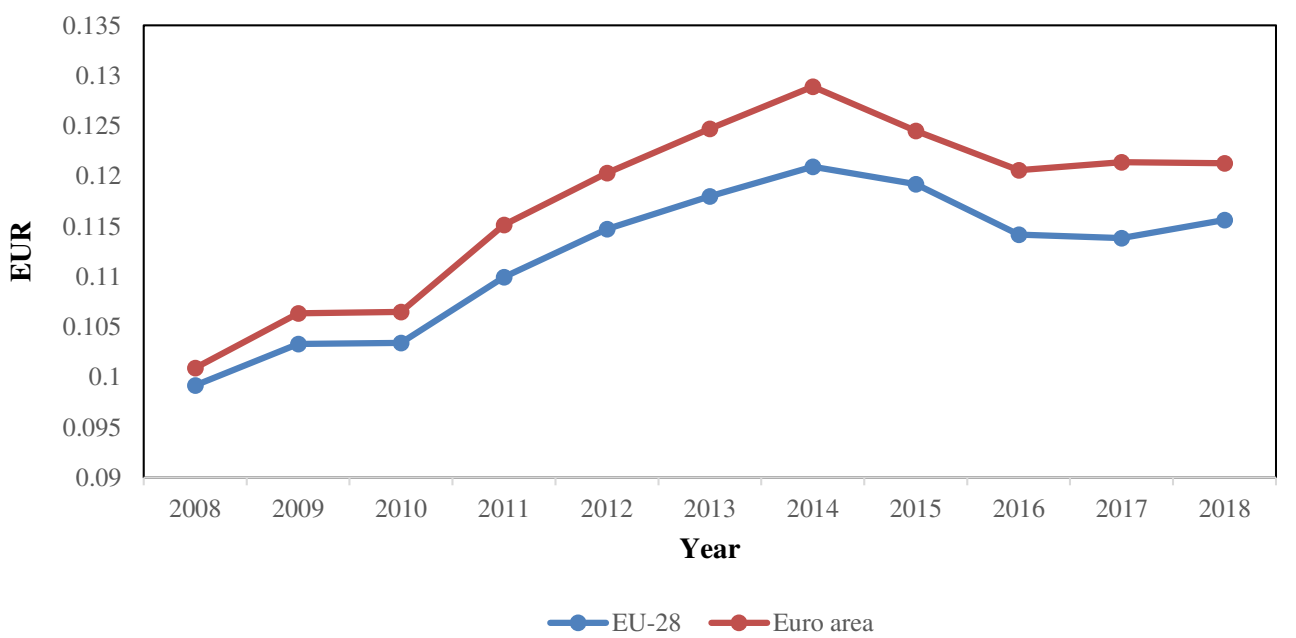


Fig. 2 Average retail electricity prices in the USA from 2008 to 2018 (USD per kWh) (Statista 2019)

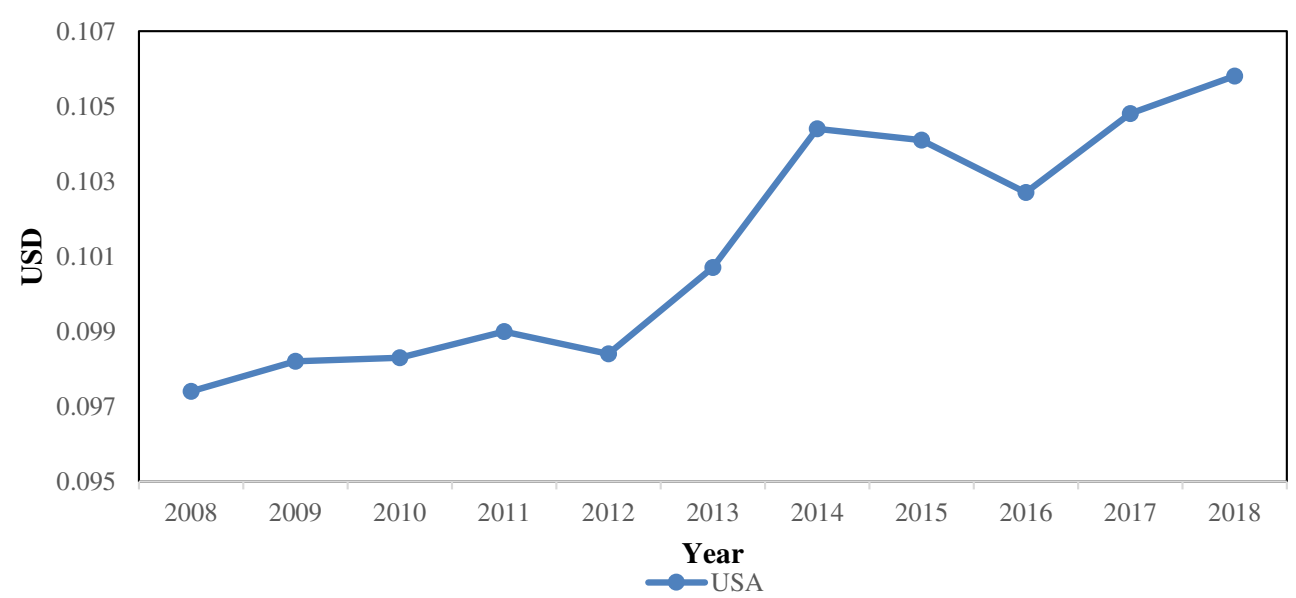

- it is possible to transport the moulds clockwise and counter-clockwise;

- the capacity of the $l_{x y}$ rail trolley accounts for 4 moulds;

- distance and transportation time are not taken into account;

- moulds are divided into requiring disassembly and reassembly, requiring cleaning and not requiring cleaning;

- the cost of one journey $k_{x y}$ from workstation $x$ to workstation $y$ is fixed and independent of load and direction of movement. It accounts for 2.56 USD.

Considering the conditions presented above, it should be decided which transport system should be selected and how many rail trolley journeys $t_{x y}$ are required so that the transportation program is completed.

\section{Mathematical description of a case study}

The research problem presented in this paper can be solved in the following 6 steps (Fig. 4).

Step I includes the following formula ingredients:

$l_{x y}$ - the capacity of the rail trolley.

$k_{x y}$ - the price of one transfer from the workstation $x$ to workstation $y$ (regardless of the load).

$t_{x y}$ - the necessary number of journeys.

$r_{x y}$ - percentage demand of the precast concrete plants $i$ for steel reinforcement type $k$.

$x_{i j}$ the number of moulds to be transported from workstation $x$ to workstation $y$.

Step II refers to defining the formula for the minimum number of $t_{x y}$ journeys. The formula is the following:

Fig. 3 The share of fuels in the production of electricity worldwide (World Coal Association 2020)

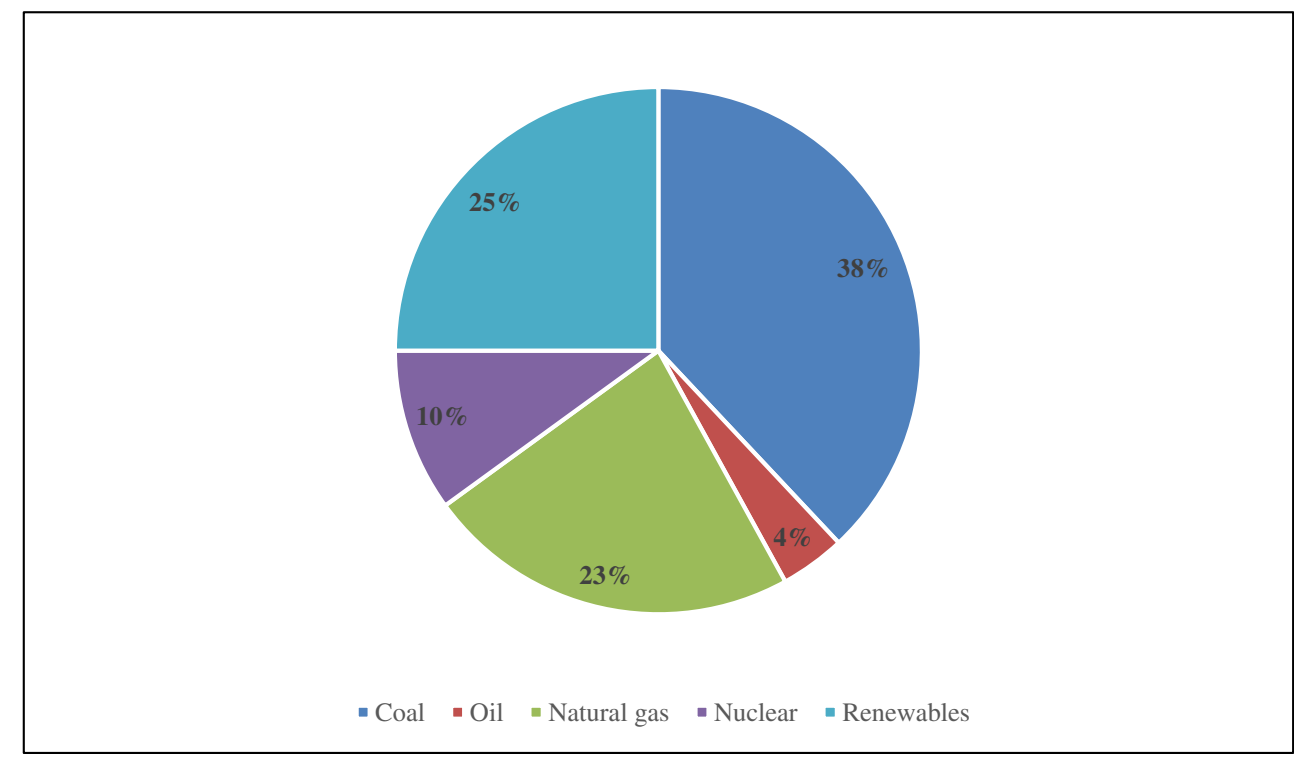


Table 2 The number of steel moulds to be transported between the workstations $x, y, z$

\begin{tabular}{|c|c|c|c|c|}
\hline & Recipient: & $\begin{array}{l}\text { Workstation } \\
\text { I-mould } \\
\text { cleaning }\end{array}$ & $\begin{array}{l}\text { Workstation } \\
\text { II_assembly } \\
\text { of moulds }\end{array}$ & $\begin{array}{l}\text { Workstation } \\
\text { III-casting }\end{array}$ \\
\hline \multirow[t]{3}{*}{ Sender: } & $\begin{array}{c}\text { Workstation } \\
\text { I-mould } \\
\text { cleaning }\end{array}$ & 0 & 7 & 9 \\
\hline & $\begin{array}{l}\text { Workstation } \\
\text { II- } \\
\text { assembly } \\
\text { of moulds }\end{array}$ & 10 & 0 & 8 \\
\hline & $\begin{array}{l}\text { Workstation } \\
\text { III- } \\
\text { casting }\end{array}$ & 8 & 9 & 0 \\
\hline
\end{tabular}

$\sum_{x=1}^{m} \sum_{y=1}^{m} k_{x y} t_{x y} \rightarrow$ minimum

\section{for: $x \neq y$.}

In step III, the condition of non-negativity of $t_{x y}$ and $s_{x y z}$ variables must be met. In addition, the variables $t_{x y}$ and $s_{x y z}$ must be integers.

$$
\begin{aligned}
& t_{x y} \geq 0 \text { and } s_{x y z} \geq 0 \\
& \text { where: } \\
& t_{x y}, s_{x y z} \text {-integers. } \\
& x, y, z=1,2, \ldots, m . \\
& x \neq y . \\
& x \neq z .
\end{aligned}
$$

Step IV defines, by the following formula, that the trolley cannot be overloaded:

$l_{x y} t_{x y}-\sum_{z=1}^{m} s_{x y z} \geq 0$

where:

$l_{x y}$ - the capacity of the rail trolley.

$x, y=1,2, \ldots, m$ and $x \neq y$.

In step $\mathrm{V}$, calculation of the minimum number of $t_{x y}$ journeys for shuttle transportation system is based on the following procedure:

$$
\text { I. If } r_{x y}=r_{y x} \text {, then }
$$

$t_{x y}=\frac{\left(r_{x y}+r_{y x}\right)}{l_{x y}}$
Fig. 4 Proceeding steps for determining the minimum number of journeys
I. Defining ingredients $l_{x y}, k_{x y}, t_{x y}, r_{x y}$ and auxiliary variable $s_{x y z}$ in the formulas.

II. Defining the formula for the minimum number of $t_{x y}$ journeys.

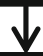

III. Defining the condition that variables $t_{x y}, s_{x y z}$ cannot be negative and must be integers.

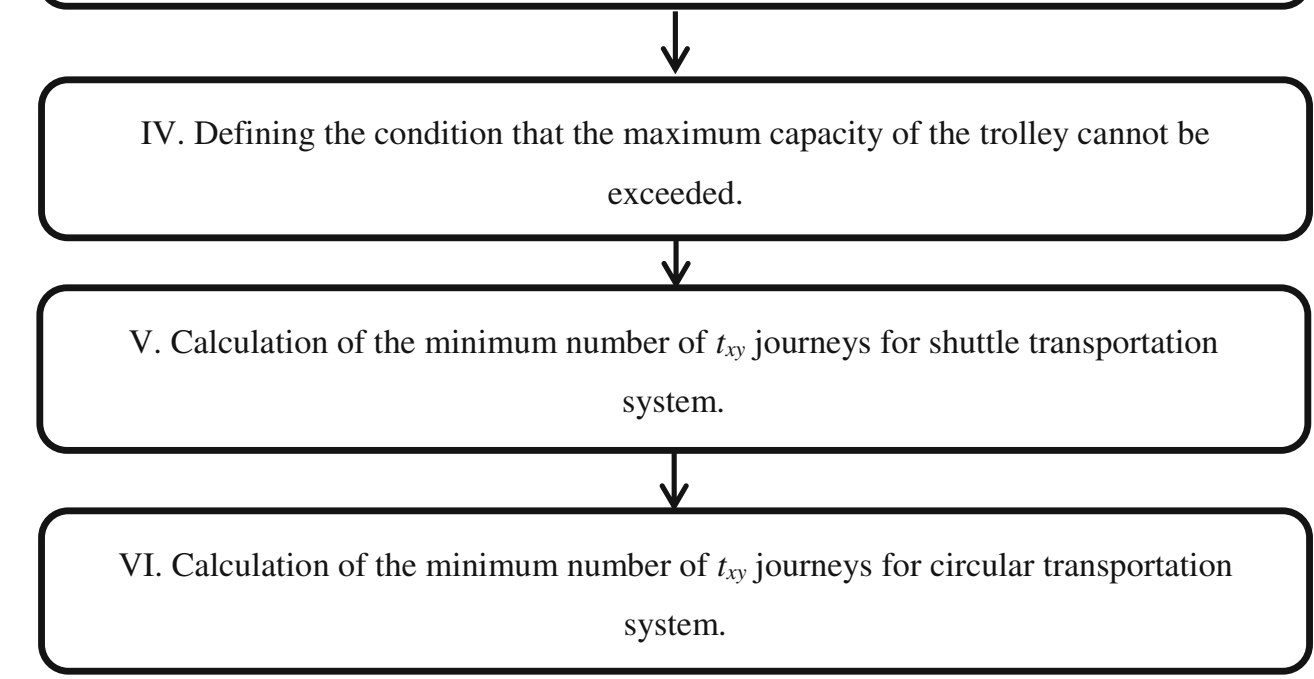


Fig. 5 Percentage of rail trolley loading in the shuttle transportation system

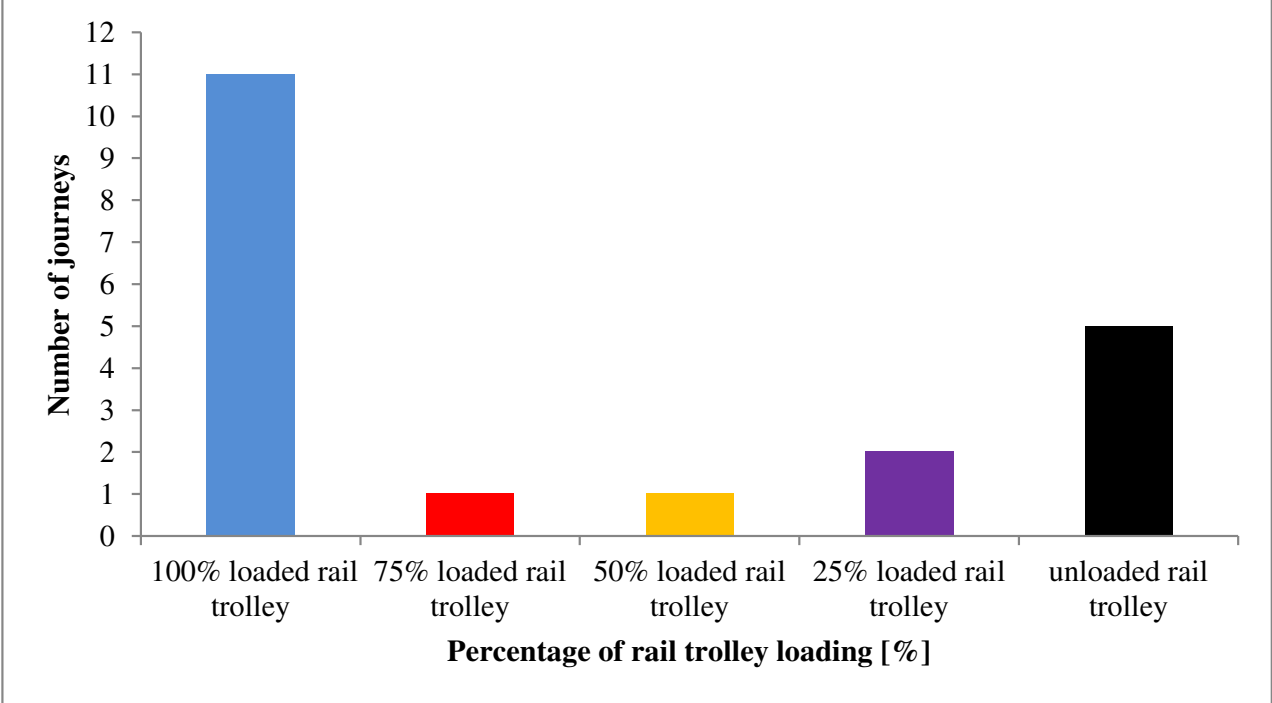

II. If $r_{x y}=0$ or $r_{y x}=0$, then

$t_{x y}=\frac{2 \cdot r_{y x}}{l_{x y}}$ or $t_{x y}=\frac{2 \cdot r_{x y}}{l_{x y}}$

III. If $r_{x y} \neq r_{y x}$ and $r_{x y}>0$ and $r_{y x}>0$, then

$t_{x y}=2 \cdot \frac{\left[\max \left(r_{x y} ; r_{y x}\right)\right]}{l_{x y}}$

If the result of the following expression:

$\frac{\left[\max \left(r_{x y} ; r_{y x}\right)\right]}{l_{x y}}$

is not an integer, then it should be round up to the nearest integer.

Fig. 6 Percentage of rail trolley loading in the circular transportation system
The number of sending workstations $x$ and receiving workstations $y$ affects the total number of routes that are determined by the following formula:

$s=2 x \cdot \frac{x-1}{2}$ or $s=2 y \cdot \frac{y-1}{2}$

where:

$x=y$.

$x, y$ - integers.

Depending on the number of sending workstations $x$ and receiving workstations $y$, the minimal number of completely underloaded journeys is determined by the following formula:

$c=x-1$ or $c=y-1$

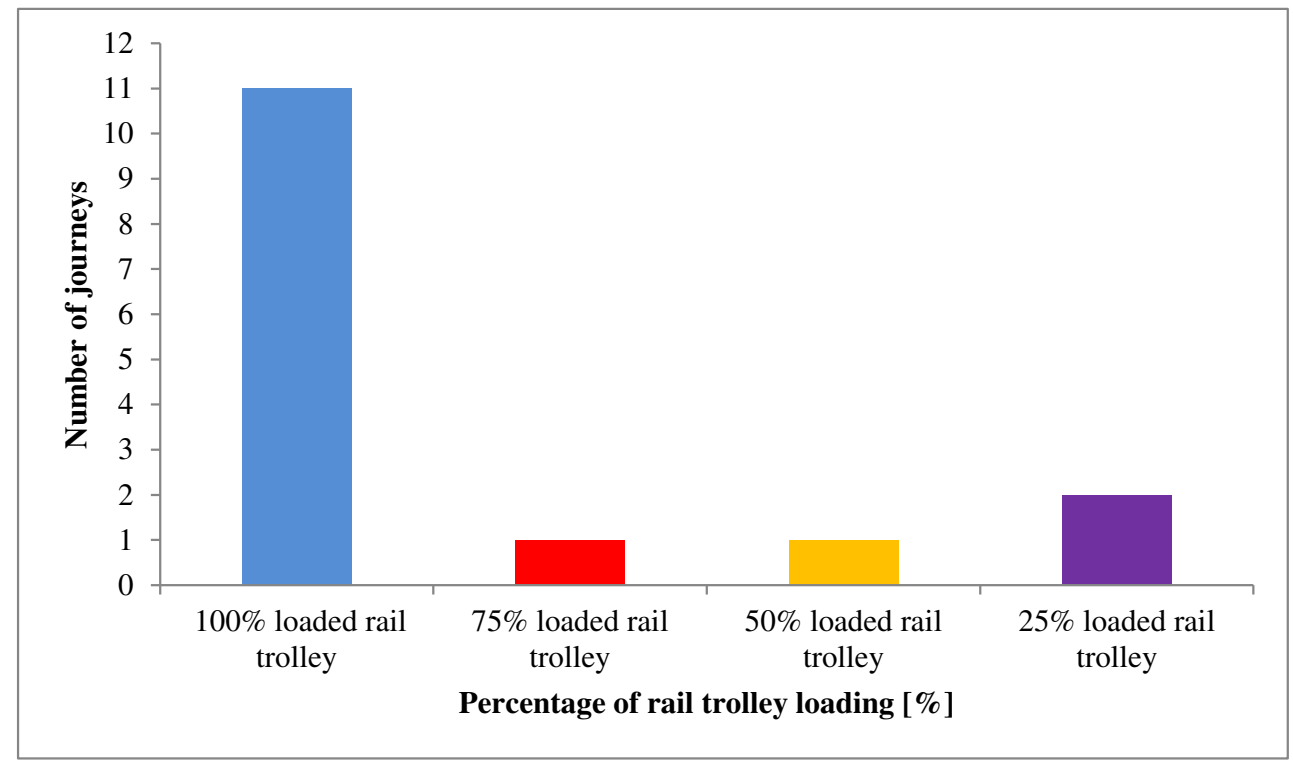


Fig. 7 Right-hand circular route of the rail trolley for the circular transportation system where:

$x=y$.

$x, y$-integers.

$x, y=2,3, \ldots, \mathrm{m}$.

It should be emphasized that this formula does not specify the total number of underloaded journeys.

In step VI, calculation of the minimum number of $t_{x y}$ journeys for circular transportation system is based on the procedure of entering the $s_{x y z}$ variables, with the following condition:

$s_{x y z}$ - positive integers.

$x \neq y \neq z$.

\section{Results achieved}

The total number of moulds to be transported accounts for 51 . Based on the data in Table 2 with the capacity of the rail

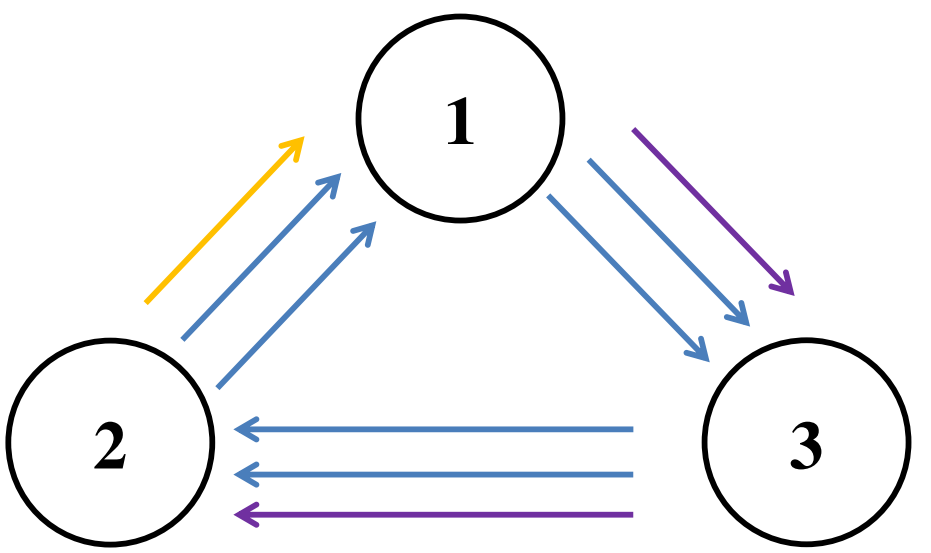

$50 \%$ loaded rail trolley

$25 \%$ loaded rail trolley trolley amounting to $l_{x y}=4$ moulds, the number of necessary journeys for the shuttle transportation system is calculated according to the following formulas:

$t_{12}=2 \cdot \frac{[\max (7 ; 10)]}{4}=2 \cdot \frac{10}{4}=2 \cdot 3=6$

$t_{23}=2 \cdot \frac{[\max (8 ; 9)]}{4}=2 \cdot \frac{9}{4}=2 \cdot 3=6$

$t_{13}=2 \cdot \frac{[\max (9 ; 8)]}{4}=2 \cdot \frac{9}{4}=2 \cdot 3=6$

The total number of routes that are determined by the following formula:

$s=2 \cdot 3 \cdot \frac{3-1}{2}=6 \cdot 1=6$

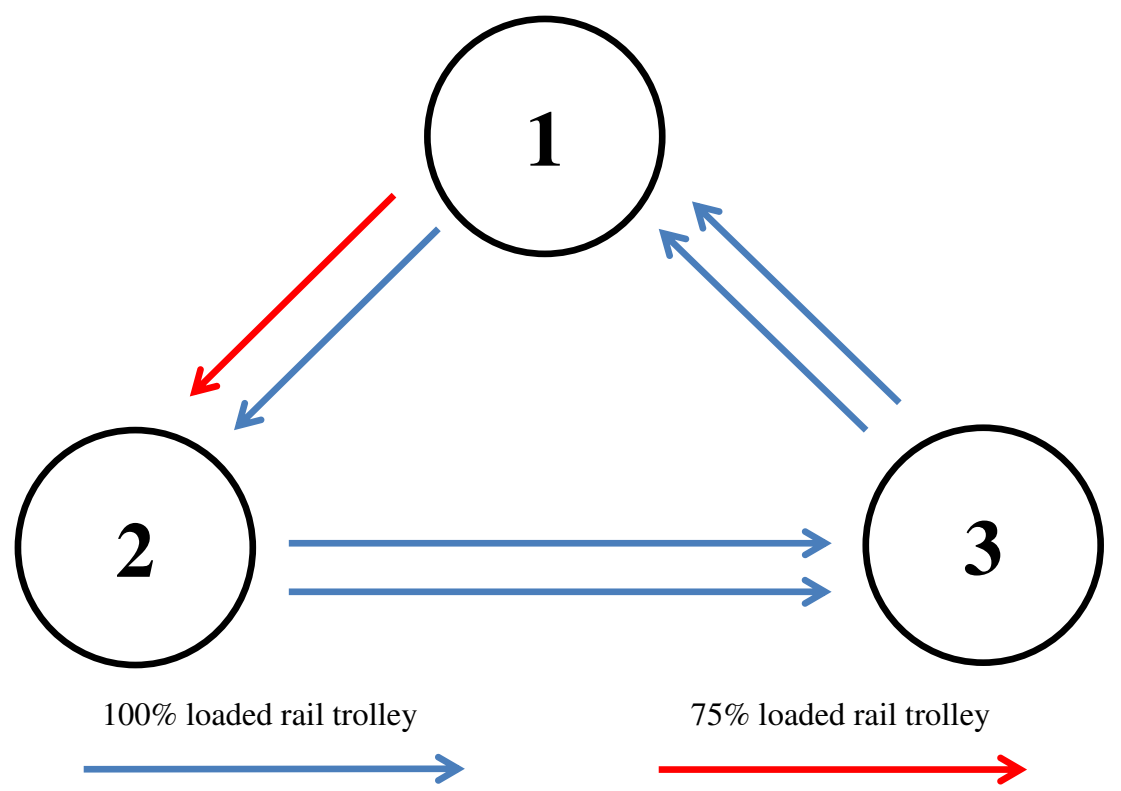

Fig. 8 Left-hand circular route of the rail trolley for the circular transportation system 
In this case, the routes are the following: $t_{12}, t_{21}, t_{23}, t_{32}, t_{13}$, $t_{31}$. The minimal number of completely underloaded journeys is determined according to the formula:

$c=3-1=2$

The total number of journeys in the shuttle transportation system for $i=j=3$ is calculated according to the formula:

$J_{S}=\sum_{x, y=1}^{3} t_{x, y}+c=6+6+6+2=20$, where $x \neq y$

The percentage of rail trolley loading depending on the number of journeys is shown in Fig. 5.

The use of a circular transportation system enables the limitation in the number of journeys, including the number of unloaded journeys. Two variables $s_{213}$ and $s_{231}$ describe the journey from sender 2 through receiver 1 to receiver 3 and from sender 2 through receiver 3 to receiver 1 , respectively. The introduction of 2 journeys $s_{213}$ and 1 journey $s_{231}$, both with $100 \%$ loaded rail trolley, enables transportation of 36 moulds, reducing the total number of journeys to 15. Additionally, the elimination of unloaded journeys has been obtained. The accurate percentage of rail trolley loading depending on the number of journeys in the circular transportation system is shown in Fig. 6.

In both transportation systems, the assumption was made that the rail trolley starts and returns finally to station 2 . The right-hand circular route of the rail trolley is shown in Fig. 7.

The total number of moulds transported in the right-hand route accounts for 28 moulds. In Fig. 8, left-hand circular route of the rail trolley is presented.

The total number of mould transported in the right-hand route amounts to 23 moulds. After completing all the six steps and considering the cost of one journey $k_{x y}$ from workstation $x$ to workstation $y$ that is equal to $2.56 \mathrm{USD}$, the following results have been obtained (Table 3 ).

Table 3 The comparison of the total cost of transportation between workstations $x$ and $y$ in the shuttle and the circular transportation systems

\begin{tabular}{|c|c|c|c|}
\hline $\begin{array}{l}\text { Sending } \\
\text { workstation } \\
x\end{array}$ & $\begin{array}{l}\text { Receiving } \\
\text { workstation } \\
y\end{array}$ & $\begin{array}{l}\text { Cost in shuttle } \\
\text { transportation } \\
\text { system (USD) }\end{array}$ & $\begin{array}{l}\text { Cost in circular } \\
\text { transportation system } \\
\text { (USD) }\end{array}$ \\
\hline 1 & 2 & 10.24 & 5.12 \\
\hline 2 & 1 & 10.24 & 7.68 \\
\hline 1 & 3 & 7.68 & 7.68 \\
\hline 3 & 1 & 7.68 & 5.12 \\
\hline 2 & 3 & 7.68 & 5.12 \\
\hline 3 & 2 & 7.68 & 7.68 \\
\hline Totally & & 51.20 & 38.40 \\
\hline
\end{tabular}

The total number of moulds is equal to 51, while the total number of journeys in the shuttle and circular transportation systems accounts for 20 and 15, respectively. Considering the rail trolley capacity, accounting for 4 moulds, the conditions formulated in step IV are also met.

\section{Conclusion}

The study established proceeding steps for determining the minimum number of journeys between workstations in the precast concrete plants, considering optimization in terms of cost. For experimental purposes, a case study of three workstations with a different number of moulds to be transported was used. Moreover, it was assumed that the capacity of each rail trolley amounts to 4 moulds, and the cost of transportation between the workstations is constant. The proceeding steps developed in this study enabled the selection of the optimal transportation system, ensuring the maximum use of the rail trolley capacity while maintaining the minimum number of journeys. The calculations had an assumption that variables cannot be negative and must be integers. The results show that the adopted assumptions to optimize transportation between workstations are effective. The presented model of proceeding, based on six subsequent steps, is a practical and clear procedure for the decision-making processes concerning the minimum number of journeys inside the precast concrete plant. Finally, the use of the circular transportation system influenced the reduction of costs by $25 \%$ compared to the shuttle transportation system. The need to select the optimal transportation system also results from the fact that the costs of electricity have raised, recently. The electricity prices in the European Union and in the USA in the last decade were also analyzed. This allowed examining the tendency of electricity prices to change over years in different markets and its reference to global predictions. Further research areas should concern the development of models enabling the selection of optimal strategies for multi-station production lines with various transportation programs. Planning the optimal transportation system, in this case, becomes a complex problem that goes beyond linear programming. Additionally, the research should address the developing of models combining optimal transportation planning and scheduling for production, as well as planning and further resource allocation strategies with regard to time-cost optimization.

\section{Declarations}

Conflict of interest The author declares that there is no competing interests. 
Open Access This article is licensed under a Creative Commons Attribution 4.0 International License, which permits use, sharing, adaptation, distribution and reproduction in any medium or format, as long as you give appropriate credit to the original author(s) and the source, provide a link to the Creative Commons licence, and indicate if changes were made. The images or other third party material in this article are included in the article's Creative Commons licence, unless indicated otherwise in a credit line to the material. If material is not included in the article's Creative Commons licence and your intended use is not permitted by statutory regulation or exceeds the permitted use, you will need to obtain permission directly from the copyright holder. To view a copy of this licence, visit http://creativecommons.org/licenses/by/4.0/.

\section{References}

Eurostat (2019) Electricity prices for non-household consumers - bi-annual data (from 2007 onwards). Code: nrg_pc_205. Retrieved February 10, 2020, from https://ec.europa.eu/eurostat

Ibadov N (2016) Determination of the risk factors impact on the construction projects implementation using fuzzy sets theory. Acta Phys Pol A 130(1):107-111. https://doi.org/10.12693/APhysPolA.130.107

Ibadov N (2018) Construction project planning under fuzzy time constraint. Int J Environ Sci Technol 16:4999-5006. https://doi.org/ 10.1007/s13762-018-1695-x

INSTITUE FOR ENERGY RESEARCH (2016) The escalating cost of electricity. Retrieved February 11, 2020, from https://www.statista. com

Khalli A, Chua DK (2013) Integrated prefabrication configuration and component grouping for resource optimization of precast production. J Constr Eng Manag 140(2):04013052. https://doi.org/10. 1061/(ASCE)CO.1943-7862.0000798

Nesheli MM, Ceder A (2014) Optimal combinations of selected tactics for public-transport transfer synchronization. Transportation Research Part C: Emerging Technologies 48:491-504. https://doi. org/10.1016/j.trc.2014.09.013

Nicał AK (2018a) Optimization of aggregates supply for concrete plants, Archives of Civil Engineering. Arch Civ Eng 64:99-110. https://doi. org/10.2478/ace-2018-0032

Nicał AK (2018b) Enhancing lean concept in precast concrete manufacturing with advanced material requirements planning system. In Creative Construction Conference Proceedings 453458 Diamond Congress Ltd. https://doi.org/10.3311/CCC2018-060

Nicał A (2019) Optimization of reinforcement steel supply to precast concrete plants. Arab J Geosci 207(12):1-9. https://doi.org/10. 1007/s12517-019-4347-7

Nicał A, Anysz H (2019) The quality management in precast concrete production and delivery processes supported by association analysis. International Journal of Environmental Science and Technology 1-14. https://doi.org/10.1007/s13762-019-02597-9

Nicał AK, Wodyński W (2015) Procuring governmental megaprojects: case study. Procedia Engineering 123:342-351. https://doi.org/10. 1016/j.proeng.2015.10.045

Nicał A, Foremny A, Kluczuk P (2014) Measurement of selected risks in the construction manufacturing plant using statistical method. Procedia Engineering 85:393-402. https://doi.org/10.1016/j. proeng.2014.10.565

Parbo J, Nielsen OA, Prato CG (2014) User perspectives in public transport timetable optimization. Transportation Research Part C: Emerging Technologies 48:269-284. https://doi.org/10.1016/j.trc. 2014.09.005

PROMAG (2019). Retrieved August 13, 2020, from https://promag.pl

Radzikowski W, Z. Sarjusz-Wolski (1994) Metody Optymalizacji Decyzji Logistycznych. Toruń: Toruńska Szkoła Zarządzania

Salicru M, Fleurent C, Armengol JM (2011) Timetable-based operation in urban transport: Run-time optimisation and improvements in the operating process. Transp Res A Policy Pract 45:721-740. https:// doi.org/10.1016/j.tra.2011.04.013

Sels P, Dewilde T, Cattrysse D, Vansteenwegen P (2016) Reducing the passenger travel time in practice by the automated construction of a robust railway timetable. Transp Res B Methodol 84:124-156. https://doi.org/10.1016/j.trb.2015.12.007

Shin K et al. (2005) Study on the storage and transportation optimization of prefabrication factory. $22^{\text {nd }}$ International Symposium on Automation and Robotics in Construction ISARC - September 11-14, Ferrara (Italy)

Shin K, Liu S, Huang C (2008) Precast storage and transportation planning via compenent zoning optimization. Robotics and Automation in Construction:159-174

Statista (2019) Retrieved February 10, 2020, from https://www.statista. com

World Coal Association (2020) Retrieved February 10 from https://www. worldcoal.org 